\title{
TEATRO ALAS D’ CUBA: SU IMPRONTA EN LA CREACIÓN TEATRAL BAYAMESA
}

\section{TEATRO ALAS D’ CUBA: ITS IMPRINT ON BAYAMESA THEATRICAL CREATION}

\author{
Leanet Peña Quintana* \\ Susell Gómez González** \\ Karina Riverón Hernández ${ }^{* * *}$
}

RESUMEN

El artículo constituye el resultado de una investigación realizada durante septiembre de 2012 a mayo de 2013, con el objetivo de analizar la importancia de la creación del grupo de teatro profesional Alas D' Cuba, dentro de la creación teatral de la ciudad de Bayamo. A partir de la utilización de entrevista, se obtuvo los criterios de expertos y miembros fundadores del mismo, con la finalidad de definir los rasgos distintivos y evidenciar la calidad y aire renovador que este grupo impregna en la ciudad de Bayamo, Cuba.

PALABRAS CLAVE: CUBA * TEATRO * HISTORIA * CULTURA * EDUCACIÓN ARTÍSTICA

\section{ABSTRACT}

The article is the result of research conducted during September 2012 to May 2013, with the aim of analyzing the importance of creating professional theater group Alas D' Cuba in theatrical creation of the city of Bayamo. Through interviews we obtained expert and founding members judgment, in order to define the distinctive features and demonstrate the quality and renovation that this group permeates in the city of Bayamo, Cuba.

KEYWORDS: CUBA * THEATRE * HISTORY * CULTURE * ART EDUCATION

\footnotetext{
* Departamento de Estudios Socioculturales de la Universidad de Granma, Cuba. sgomezh@udg.co.cu

** Departamento de Estudios Socioculturales de la Universidad de Granma, Cuba. sgomezh@udg.co.cu

*** Departamento de Estudios Socioculturales de la Universidad de Granma, Cuba. kriveronh@udg.co.cu
} 
En cierta ocasión cuando Esquilo era un niño, su padre lo mandó al viñedo, a vigilar que nadie robara la uva madura, según una leyenda antigua .Se quedó dormido y tuvo un sueño en el que se le apareció Dionisios, el dios del vino y la alegría, y le ordenó que escribiera una tragedia. La escribió, y otra y después otra más hasta cerca de noventa llegando a convertirse en uno de los tres mejores poetas dramáticos que jamás hayan existido.

(Barba y Savarese, 1982: 81)

Desde el siglo xviI, se había venido desarrollando un teatro en Cuba que pretendía hacer reír, la búsqueda de un producto cubanizado, transformado en un espejo de la realidad. Se plantea que ese género se inició en Cuba, en 1842, con la obra Una Aventura o El Camino más corto, de José Agustín Millán, posteriormente continuó perfeccionándose.

Para poner un broche de dignidad al teatro cubano, el día 23 de enero de 1869 , es publicado un pequeño periódico donde aparecía la obra de José Martí: Abdala. Se puede afirmar que con Abdala nace un nuevo teatro, el teatro mambí, el cual se presentaba en los campamentos mambises $y$ desde luego, fue representado en el exilio por los cubanos, donde tuvo una abundante creación.

Hasta la década del 50, comienza a emerger un teatro de transición, del cual se destacan tres figuras: Virgilio Piñera Llera, Carlos Felipe y Rolando Ferrer. Estos autores pusieron el teatro cubano a la altura de su tiempo y lo modernizaron con técnicas universales, superando con creces al teatro de corte vernáculo.

Al triunfar La Revolución, se tomaron medidas que contribuirían al desarrollo del teatro cubano. En junio de 1959, se dicta la ley de creación del Teatro Nacional y se produce la formación de numerosos grupos teatrales financiados por el Estado.

A partir de ese momento, todas las provincias contaron con grupos teatrales integrados por actores y actrices de formación profesional que han estado al lado de su pueblo, reflejando el desarrollo de una sociedad enfrascada en construir un proyecto social justo $y$ buscando contribuir a elevar el nivel cultural y de apreciación del público.
La provincia de Granma entra a la historia del teatro cubano en el año 1977, con la aparición en sus tablas del Colectivo Teatral Granma (ст)) pionero de la profesionalización teatral. En el recorrido histórico por el teatro en la ciudad de Bayamo, interesa fuertemente la consolidación de una escena que apunta en nuevas direcciones, ampliando la estética de un teatro de arte, Teatro Alas D' Cuba, el cual se esgrime en un movimiento vanguardista de la creación que trae consigo una nueva mirada sobre el panorama teatral. Sin embargo, como una tendencia en el análisis teórico, en el contexto cubano priman las investigaciones en el campo artístico, no así en el campo cultural, sin limitar la mirada al hecho escénico desde posturas sociológicas a partir de su importancia y su representación, de ahí su contribución en la formación de dinámicas de relación teatrocontexto artístico cultural.

Actualmente, en el contexto bayamés se mantienen cinco grupos profesionales de teatro: el iniciador y padre de la profesionalización teatral en Bayamo, el Colectivo Teatral Granma con una trayectoria de 36 años y una línea de desarrollo, siendo la comedia su principal forma de trabajo. Le siguen el Teatro Alas D Cuba, Guerrilla de teatreros, Pequeño Príncipe (para niños) y Teatro Callejero Andante.

Se persigue con este artículo valorar la importancia que tiene el grupo de "Teatro Alas D' Cuba" a partir de la identificación de sus rasgos distintivos dentro de la creación teatral bayamesa desde su surgimiento hasta la actualidad.

\section{APUNTES DE LA CREACIÓN TEATRAL BAYAMESA}

La historia teatral bayamesa se caracteriza y tiene puntos en común con el propio sentido del teatro en su historia en Cuba. Nace comprometido con la situación socioeconómica y política, reflejándola, criticándola o en ocasiones, siendo un mecanismo de evasión y frustración de los más altos ideales de independencia contra el poder colonial.

Estas formas que caracterizan el teatro cubano, también caracterizan la formación de este como proceso de desarrollo en Bayamo, el pueblo colonial. Durante la etapa republicana 
muchos fueron los intentos por lograr un teatro apasionado y comprometido que reflejara las condiciones de la sociedad y que a su vez, sirviera para culturizar la sociedad bayamesa.

La sociedad criolla -surgió desde el siglo xVI- se organizó durante el siglo xvir y se consolidó en el siglo xviII. Las grandes industrias de la Isla (tabaco y azúcar) nacieron y se desarrollaron gradualmente; así como se acumularon riquezas y las clases sociales tomaron características más firmes. El mundo del criollo que se estaba configurando fue representado $y$ recreado artísticamente por Silvestre de Balboa Troya y Quesada en su reconocida obra Espejo de Paciencia, en 1608.

Esta historia tiene raíces en un pasado lejano, cuando en 1840, los hombres ilustrados de Bayamo laboraron con tesón para crear un ambiente más culto y civilizado. Las batallas por la educación y la cultura resultaban muy difíciles en los tiempos de la colonia. El despotismo no tenía límites, pues privaba a los cubanos de todos sus derechos. No se concebía otro recurso que callar y obedecer. Pero a mediados del siglo xix, los bayameses decidieron cambiar la monotonía y la calma que los sofocaba (Muñoz, 2007).

Precisamente es en este periodo donde se aspiraba a crear una sociedad cultural donde los procesos económicos, las ideas políticas, el modo de vida y la creación artística tuvieran mayor dinamismo y complejidad, a través de la materialización de varios proyectos culturales en la ciudad.

En relación con las manifestaciones artísticas que caracterizaron el movimiento cultural de la época y constituyeron un reflejo de aquella sociedad, se debe plantear la participación destacada de Carlos Manuel de Céspedes, Esteban Estrada, Pedro Figueredo, Francisco Castillo Moreno, Francisco Vicente Aguilera, Eugenio Eduardo, Francisco y Lucas del Castillo, Eligio Izaguirre, entre otros. En su mayoría de clase acaudalada $y$ figuras cimeras no solo de la cultura y de los distintos centros para promover el arte en la ciudad, sino patriotas que contribuyeron a la causa independentista. A destacar, el ejemplo de Pedro Figueredo o Perucho quien compuso la letra del Himno de
Bayamo, hoy Himno Nacional. También Carlos Manuel de Céspedes, quien dio la libertad a sus esclavos el 10 de octubre de 1868, iniciando la lucha independentista $y$ a su vez, trabajó como actor de teatro en las ciudades de Bayamo y Manzanillo.

Fueron muchos los intentos por lograr un cambio en el espectro cultural de la ciudad, pero no es hasta 1840 que se comienza a palpar el avance y la transformación del mismo con la fundación de la Academia de Música, constituyéndose ese mismo año "La Sociedad Filarmónica de Bayamo":

... se congregaba lo más selecto de la sociedad bayamesa. Tenía como objetivo primario la difusión de la cultura y la instrucción en sus diversas formas. Sus miembros se consagraron con empeño al cultivo de las letras, la música, el teatro; a impulsar el buen comportamiento ciudadano y el estudio de las causas de los males sociales. Contó con la presencia de músicos como: Ramón Borrero, Joaquín Oduardo, Manuel Muñoz Cedeño; con los poetas Úrsula de Céspedes, Lucas del Castillo, José Joaquín Palma, y otros. De ahí que, constituya punto esencial de expresión del sentido de cubanidad que se desarrollaba (Cobas, 2008: 22).

Esta sociedad fue creada con el objetivo de integrar diversas manifestaciones artísticas como son la literatura, la declamación, el canto, la música, el baile y el teatro, convirtiéndose en el espíritu de la cultura bayamesa. A través de la misma se expresaban ideas, aspiraciones $y$ estados de ánimo que caracterizaban el sentir del pueblo bayamés contra el régimen dominante.

Es en esta etapa donde se estaba llevando el proceso de construcción de teatros en las diferentes ciudades del país y en el caso de Bayamo, se destaca el aporte de Francisco Vicente Aguilera, donando 800 mil pesos para la construcción de un teatro, lo cual fue motivo de inspiración para las demás personas quienes también aportaron para la creación de esta institución de gran repercusión en la historia de la ciudad. 
...El mismo comenzó a erigirse en la manzana 29 que se interponía entre el callejón de Juan Burruchaga (hoy calle General Antonio Maceo) y la Plaza de Armas (hoy Plaza de la Revolución). Una junta encabezada por Céspedes, Fornaris y Aguilera redactó el reglamento de dicha institución, documento del cual se tiene muy pocas noticias. Una de las ideas rectoras era destinar parte del dinero recaudado en las funciones al Hospital de Caridad San Roque, situado en la calle de Las Piñas (hoy calles Máximo Gómez) (Muñoz, 2007: 16).

Esta institución fue escenario de obras adaptadas por los ilustrados de la época, como es el caso de Carlos Manuel de Céspedes, José Fornaris, Perucho Figueredo y Francisco del Castillo, de los dos últimos no se tiene una constancia de su trabajo.

Dos respetables obras de dramaturgos franceses fueron llevadas a las tablas bien interpretadas y adaptadas por Céspedes: $E l$ cervecero del rey de Florencio Dancourt y Las dos dianas de Alejandro Dumas. Estas tuvieron buena aceptación, especialmente la última, que fue presentada en la inauguración del primer salón de la región el 25 de julio de 1845, durante las fiestas de Santa Cristina y Santiago.

En el año 1849, fue presentado por Céspedes en la escena cubana la obra dramática "El conde de Montgomery", en la cual se hace alusión a las ansias de libertad de un pueblo. Por tales ideas fue apresado y luego desterrado, estableciéndose en la ciudad de Manzanillo, incorporándose a la sociedad teatral y contribuyendo a el desarrollo con la creación de un grupo dramático, siendo capaz de montar obras de su autoría e incluso, actuando en algunas de ellas.

Asimismo, se montaron obras teatrales de José Fornaris, en las cuales vibran las costumbres esenciales de los diversos grupos sociales de la colonia: el drama La hija del pueblo más conocida como "Lola la tejedora" y otro drama, Amor y sacrificio.

A partir del año 1869, se anuló la actividad teatral en las ciudades de Cuba. La dramaturgia cubana se desarrolla dentro de la isla o en el exilio, no obstante, la que se lleva a cabo en la Isla se puede dividir a su vez en dos, la que se desarrolla en los campamentos mambises y la que se producía solo en La Habana y ocasionalmente, en alguna otra ciudad, las cuales serían representaciones de un teatro plegado a la colonia y a los intereses de las autoridades gobernantes.

El avance teatral que fue alcanzado en la etapa colonial se ve frustrado por los diferentes acontecimientos que rodeaban la ciudad, con lo que provocó un vacío en el espacio teatral de la provincia durante 60 años y que renacería en septiembre de 1912, con la apertura de un nuevo teatro.

Desde 1902, dentro del panorama sociopolítico de Bayamo, comenzaron a incidir de manera más pujante y progresiva las inquietudes de la incipiente clase obrera, agrupada en los gremios de tabacaleros y albañiles. Los grupos de trabajadores demandaban la apertura de escuelas, el pago en moneda americana de mucho más valor que la española y se pronunciaban contra el control extranjero sobre los puestos de trabajo, fundamentalmente en el sector estatal (Fonseca y Naranjo, 2011).

En septiembre de 1912, el Salón Teatro Oriente, empresariado por Joaquín Martí, abre sus puertas en Bayamo, generando un movimiento teatral en el territorio. La actividad demandaba cuantiosos recursos que eran empleados por los dueños para traer compañías extranjeras de prestigio, antes que invertir en los posibles talentos del patio. Por este, como por el resto de los cines teatros de la época, pasaron importantes compañías teatrales: la de Martínez Casado, Bolito, Spigul, entre otras. El Diario La Polémica, el 31 de julio de 1919, anunció la presentación de la Compañía de Dramas y Comedias "Serrador Mari", con la comedia Papá Lebonnard del académico francés Mister Aycard (Iglesias, 2011).

A pesar de todo lo ocurrido en el espectro teatral nacional, en la ciudad de Bayamo también se dieron disimiles acontecimientos como ejemplos de un creciente desarrollo de libertad nacionalista en todos los planos, incrementando 
ese sentimiento antiimperialista, desestimando la politiquería, el fraude y la corrupción.

La sociedad bayamesa se propuso seguir adelante con su quehacer artístico cultural, por lo cual aparecen las publicaciones de diferentes revistas, diarios, periódicos, novelas, etc. Entre estas se destacan: El diario de Bayamo (1917), el periódico El Heraldo de Bayamo (1920), el periódico El Derecho (1925), las obras literarias aparecieron con el poemario Vuelo y cumbre de Juan Jerez Villareal (1922), la novela La Raza Triste (1924) de Jesús Masdeu y muchos otros.

Estas publicaciones constituyen una vía para recoger el arduo trabajo que se estaba haciendo en la ciudad. Precisamente, en el periódico El Derecho en el año 1928, se publican los espectáculos que acontecían en el territorio, de estos se dice que tuvieron buena aceptación dado la variedad de elementos relacionados a precios asequibles, la excelente labor de las orquestas y la correcta ventilación de las edificaciones.

Por lo tanto, tal vez ese ambiente fue el que impulsó un grupo de jóvenes de la Asociación Hijos de Bayamo, a fundar una agrupación teatral. Estuvo conformada por José A. Tamayo, Policarpo Fernández, Manuel Milanés, Bernardo Suárez, José Sabater, Mario Carbonell y Secundino Milán (Muñoz, 2007). Este intrépido grupo se presentó por primera vez, el 6 de mayo de 1929, con la presentación en el teatro Bayamo de la comedia lírica Baño inesperado de Isabel Yero, además de las presentaciones de Manuel Milanés con el monólogo Vísperas de bodas de la autoría de Armando Soler y también contó con la actuación de José A. Tamayo, quien defendió el monólogo Monito de imitación del autor Enrique Arias.

A partir de este momento, la actividad teatral de la ciudad Bayamesa se ve en una etapa de silencio, debido al débil tratamiento $y$ apoyo por parte de los organismos e instituciones, debido a que no consiguieron las fuerzas $y$ los recursos necesarios para lograr un mejor desarrollo artístico cultural en la misma.

Posterior al triunfo revolucionario, el teatro cubano adquiere carácter nacional, encaminado a la profundización de las tradiciones y al rescate de los valores culturales de la nación.
Todo ello se hace posible a través de la implementación de la política cultural cubana.

Precisamente, es en esta etapa donde los grupos teatrales asumen una nueva perspectiva, encaminado a la estimulación de la creación artística, al aseguramiento de dicha creación y al consumo y asimilación del mismo, manifestándose verdadero desarrollo tanto de los autores como sus títulos, lo cual se logra comprobar a través del público mejor preparado y capacitado.

En el año 1976, la producción teatral se enfoca en construir un movimiento teatral más sólido y profesional en el espectro nacional, siendo los principales protagonistas de esta manifestación: Teatro Estudio, fundado en 1958 y el grupo Teatro Escambray, fundado en 1968.

La experiencia de Teatro Escambray alentó el surgimiento de otras agrupaciones en zonas rurales y urbanas del país, dando lugar al auge de un fuerte movimiento de gran alcance popular comprometido con la problemática sociopolítica. Además, forman parte de este movimiento: La Yaya, Cubana de Acero, Teatro de Participación Popular y Conjunto Dramático de Oriente, entre otros. Asimismo, se adoptó el nombre de Teatro Nuevo cobrando especial fuerza en los años 70 (Muñoz, 2007).

De tal manera llega a la ciudad de Bayamo el "Conjunto Dramático de Oriente" y posteriormente, el "Cabildo Teatral Santiago" con el que el público del territorio tuvo un acercamiento directo a un teatro de profundas raíces populares $y$ con un alto nivel profesional. Este hecho demostró a las autoridades de la provincia, la necesidad de la formación de un grupo profesional propio de la localidad.

Se crearon entonces las condiciones para que -precedentes de esta prestigiosa agrupación- se trasladaran a Granma, los teatristas Miguel Lucero y Delia Niuvó, quienes fundaron la primera agrupación teatral profesional de la provincia: Colectivo Teatral Granma, el 14 de febrero de 1977, "año de la Institucionalización". Esto permitió una nueva etapa para la manifestación artística en esta provincia.

En 1977, se funda el Colectivo Teatral Granma, significando el germen de un movimiento teatral en la provincia, a partir de 
esto comienzan a surgir otros grupos teatrales como Guiñol Sierra Maestra (1979), que actualmente lleva el nombre de Guiñol Pequeño Príncipe. En 1990, se concibe el Consejo Provincial de Artes Escénicas, logrando surgir otras agrupaciones: Teatro Andante (1991), En hora buena (1991), Ategua (1995) y Teatro Alas (1996), oficialmente constituido en el 2000.

En el periodo comprendido entre los años 70 y 80, la creación artística estaba matizada por una tendencia reflexiva, dada por los disímiles cambios en cuanto a la creación en relación con las concepciones estéticas y éticas del movimiento creativo, el mismo va aparejado con los acontecimientos socioculturales que se dan en el periodo.

El protagonismo lo tuvieron el Colectivo Teatral Granma y el Guiñol Pequeño Príncipe, los cuales mantenían el ritmo del teatro de manera dinámica, ofreciendo interesantes posibilidades artísticas, participando y representando la provincia a nivel nacional, en los festivales de teatro.

A pesar de todos los contratiempos que acontecieron en la creación teatral bayamesa, el Ministerio de Cultura llevó a cabo una política de promoción y producción teatral que va a favorecer de cierta manera, permitiendo que el público tuviera acceso al arte teatral en todos los espacios de la provincia apartados de los centros culturales, ya sean barrios, escuelas, fábricas y en las diferentes comunidades, tanto urbanas como rurales, permitiendo un amplio desarrollo de los grupos y motivando a la población.

En general, una parte del teatro cubano $y$ en particular en Granma, es muy interactivo $y$ entrecruzado, dejando notar las influencias de estilos defendidos por los maestros de más experiencia, cubanos o extranjeros, que han contribuido con fuerza en el teatro.

El teatro profesional en Granma no ha contado con un buen desarrollo creativo $y$ un elevado nivel artístico como el de sus inicios. Las causas pudieran estar relacionadas con aspectos tan diversos como: dificultades económicas o falta de una correcta política de promoción y jerarquización por parte de las instituciones relacionadas con las artes escénicas.
A pesar de todos los problemas existentes en la esfera del arte, destacando el teatro, la dirección del Gobierno Provincial se ha preocupado por la reparación de las instituciones y por la construcción de nuevos lugares que sean más amenos, en los cuales se puedan presentar los artistas del territorio e invitados de otras provincias de gran fama nacional. Se ha trabajado en la reparación de la Sala Teatro José Joaquín Palma, la construcción del Teatro 10 de Octubre y del Teatro Bayamo.

Se ha generado una preocupación en cuanto a la formación profesional de los estudiantes con talentos artísticos; se destaca la construcción de la Escuela Provincial de Arte (EPA), con la misión de la formación de profesionales en las diferentes manifestaciones artísticas y la Escuela de Instructores de Arte (EIA) que forma profesores en las diversas formas del arte, quienes a vez realizarán un trabajo arduo en escuelas y comunidades.

La profunda crisis de los años más agudos del período afectó el teatro provincial. Los colectivos buscaron opciones -fue entonces más artesanal e imaginativo-y los grupos pusieron en práctica alternativas de autogestión, las cuales han traído como consecuencia, prácticas creativas y promocionales autosuficientes y autónomas. Esta época cuenta con la urgencia de renovar la estructura $y$ el funcionamiento del teatro en el territorio, por lo que la actividad teatral no podía ir al ritmo de la realidad en el ámbito nacional, lo que provocó nuevamente, la crisis entre la relación institución y la creación artística.

\section{TEATRO ALAS D’ CUBA, NUEVO ESPACIO DE CREACIÓN TEATRAL BAYAMESA}

La virtud de producción teatral bayamesa se ve frustrada con la llegada de la década de los 90 e influyó en el desarrollo de las capacidades de los artistas. Se crearon alternativas de trabajo que influyeron positivamente a pesar de los acontecimientos, provocando que se produjera la autogestión por parte de los miembros de los grupos, manteniendo siempre una intención de crear con propósitos bien definidos y un compromiso con el público. 
A partir de los cambios proyectados hacia una nueva política de funcionamiento, aparece el CTG orientado hacia un nuevo sostenimiento, independientemente de su capacidad creativa. Aparejado a esto se proponen nuevos proyectos artísticos $y$ la puesta en escena de variedad de obras.

Con la llegada del segundo lustro de la década de los 90, el cтg cuenta con dos opciones, el cambio en su funcionamiento o la perduración en lo establecido en cuanto a las normas formales, las cuales ya rendían un mínimo de beneficio y utilidad.

Como una tercera variante, el grupo aprueba por consenso, dividirse en dos equipos de trabajo, uno representado por los miembros fundadores y otro por los actores de última incorporación, quienes se agrupaban con intenciones más comprometidas con la idea del proyecto artístico, de acuerdo con un sentido ético renovado, única manera de alcanzar los fines artísticos. El grupo compuesto por los no fundadores estrenaron el 14 de diciembre de 1996, la pieza Las Rosas de María Fonseca, original del joven dramaturgo cienfueguero Ricardo Muñoz Caravaca (Muñoz, 2007).

Con el estreno de Las rosas de María Fonseca se materializan los propósitos iniciales de un grupo de actores que formaban parte del Colectivo Teatral Granma, quienes verificaron una progresiva definición de sus posturas y propósitos estratégicos a tono con las líneas generales del nuevo modelo institucional que nacía $y$ del cual formaban parte.

El grupo surge como núcleo creativo en un típico proyecto teatral con el reconocimiento de la Unión Nacional de Escritores y Artistas de Cuba (unEac) y la Asociación Hermanos Saíz (AHS), como línea ideo-estética y no como grupo. Sus actores se agrupaban con intenciones más comprometidas y comenzaron con algunos trabajos diferentes, siempre con el apoyo y orientación del Colectivo Teatral Granma.

Sus integrantes tenían como primer gran propósito, hacer un teatro más abierto, capaz de inquietar a un público más amplio y sacudir a sus protagonistas de la pereza intelectual que a veces caracteriza la vida cultural provinciana. Ellos deseaban un teatro que definían como de vanguardia, más arriesgado, para lo que necesitaban otras prácticas y una dramaturgia más universal, sin perder nunca de vista que trabajaban para un público provincial, un público que se identificó con su trabajo, con el que establecieron desde el principio una interacción que aportó mucho a su evolución.

De 1996 al 2000, su núcleo creativo se vio obligado a pugnar por un reconocimiento institucional, en correspondencia con los resultados artísticos alcanzados. Los enfrentamientos a trabas burocráticas, indiferencias y otras contradicciones, casi hicieron colapsar el proyecto, pero este supo seguir adelante $y$ fue capaz de alcanzar un reconocimiento a nivel nacional, lo que se demostró con la obtención de premios en distintos festivales nacionales como son: Premio de Texto Casa de las Américas (1996) y premios de Mejor Puesta en Escena y Mejor Actuación Protagónica Femenina en el Festival Máscara de Caoba de Santiago de Cuba (1998).

Las presiones ejercidas por los especialistas del Consejo Nacional de Artes Escénicas y la Asociación Hermano Saíz movilizaron a las autoridades $y$ funcionarios provinciales para la fundación oficial del Teatro Alas, como grupo independiente en el año 2000. Esto con el deseo de hacer un teatro que se adaptara más al movimiento contemporáneo.

Actualmente, el grupo cuenta con 15 miembros, 5 fundadores y 10 integrantes nuevos y jóvenes, de ellos, 6 son egresados de EPA Manuel Muñoz Cedeño, 2 son graduados de la EIA "Cacique Hatuey" y el resto son de formación empírica.

Paralelamente a los estrenos y presentaciones, se ha desarrollado otra serie de actividades fuera de las salas teatrales, las cuales abarcan el trabajo con los niños a través de la técnica de clown, realizándose todos los sábados y domingos. Además, se presentan en cualquier comunidad a otros públicos (incluyendo al rural). Participan en la cruzada teatral Guantánamo-Baracoa y se presentan en la Sierra junto con la Guerrilla de Teatreros y el grupo Andante. Asimismo, se tiene un proyecto sobre lectura de textos dramáticos en la unEAc. Por otro lado, algunos de sus integrantes hacen televisión y con mayor frecuencia radio. 


\section{METODOLOGÍA}

El acercamiento informal al campo se realizó durante el año 2012, con el objetivo de recoger información sobre los miembros del grupo de teatro, en cuanto a composición y actividades realizadas regularmente, así como para conocer las características personales de los actores con el fin de detectar a aquellos individuos que podían servir de porteros para introducir el acceso formal de los investigadores. Estos coincidieron con los líderes informales del grupo, los cuales en conjunto con los demás miembros, fijaron la fecha, hora y lugar para la aplicación de los instrumentos.

Asimismo se realizaron visitas al Consejo Provincial de Artes Escénicas para contactar con los especialistas que pudieran aportar información valiosa para la investigación. En los contactos iniciales, se procedió a presentar formalmente a las investigadoras y miembros del grupo de teatro y posteriormente, se dieron a conocer los objetivos de la investigación. El estudio resultó ser de gran interés para los actores, permitiendo una mayor calidad y profundidad en la información recolectada.

Para la selección de la muestra se empleó el muestreo no probabilístico intencional con sujetos expertos y sujetos tipos, a partir de la determinación de criterios de inclusión. La muestra estuvo compuesta por dos grupos fundamentales.

El primero integrado por directivos del Consejo Provincial de Artes Escénicas, este grupo está compuesto por el presidente, vicepresidente $y$ los especialistas que se encargan de la promoción del grupo. Estos sujetos fueron considerados expertos y debían cumplir con los siguientes criterios de inclusión:

1) Llevar más de 4 años trabajando en el Consejo Provincial de Artes Escénicas.

2) Estar presentes durante el período de la investigación.

3) Voluntad de cooperar.

El segundo está integrado por los miembros fundadores del grupo Teatro Alas D' Cuba, a los cuales se les aplicó la entrevista en profundidad. Estos debían cumplir con los siguientes criterios de inclusión:

\section{1) Ser fundadores del grupo Teatro Alas D' Cuba. \\ 2) Permanecer actualmente en el grupo. \\ 3) Voluntad de cooperar.}

Dentro del segundo grupo se consideraron a todos los miembros de Teatro Alas D' Cuba como sujetos tipos. Para la selección de esta muestra se tuvo en cuenta como criterios de inclusión:

1) Ser miembro permanente de Teatro Alas D'Cuba.

2) Estar presentes durante el periodo de la investigación.

3) Voluntad de cooperar.

La muestra estuvo compuesta en su totalidad por 20 personas: 4 integrantes del Consejo Provincial de Artes Escénicas y los 16 miembros del grupo Teatro Alas D' Cuba (entre fundadores $y$ no fundadores). Los métodos $y$ técnicas en la investigación fueron:

1) ANÁLISIS Y SÍNTESIS: este método fue de vital importancia para la elaboración de la fundamentación teórica de la investigación y el análisis de los resultados, ya que permitió analizar la información obtenida acerca de la formación del teatro nacional, las características de la escena cubana y la historia teatral bayamesa, así como, la profesionalización teatral en Bayamo, permitiendo de esta manera su descomposición en partes y posterior integración para una mayor comprensión del teatro como manifestación artística.

2) HISTÓRICO-LÓGICO: fue utilizado con el objetivo de realizar el análisis lógico y secuencial del teatro nacional, a partir de su formación y posterior desarrollo hasta las particularidades del teatro bayamés actual, haciendo énfasis en el devenir histórico del grupo Teatro Alas D' Cuba. Se empleó durante la elaboración de la fundamentación teórica de la investigación. 
3) INDUCCIÓN-DEDUCCIÓN: permitió establecer generalizaciones $y$ arribar a conclusiones a partir de la información recogida acerca del grupo de teatro y sus aportes a la creación teatral bayamesa. Asimismo, se pudo arribar a razonamientos de hecho singulares que se dan en el grupo de teatro (deficiente estrategia de promoción cultural).

4) FENOMENOLOGÍA: permitió identificar la importancia del Grupo Teatro Alas D' Cuba para la cultura bayamesa, a través de la subjetividad de los individuos y analizar el fenómeno a partir de su análisis e interpretación. Además, posibilitó conocer la subjetividad de los individuos $y$ analizar el fenómeno a través de la interpretación que hicieron los actores del grupo de teatro.

Se aplicaron como técnicas, la entrevista en profundidad y las sesiones de grupo. La entrevista fue aplicada a especialistas del Centro provincial de Artes Escénicas y a miembros fundadores del grupo Teatro Alas D'Cuba y las sesiones del grupo de discusión se realizaron con todos los miembros del grupo teatral (ver anexo 3).

Las sesiones fueron grabadas con el consentimiento previo de los sujetos investigados y se registraron fotográficamente. Para facilitar el debate y la libre expresión de los participantes se realizaron en un espacio acogedor, con privacidad y se establecieron un conjunto de normas de trabajo en grupo. El tema se abordó partiendo de lo general a lo particular de la investigación. El criterio de culminación para las sesiones y el cierre del grupo fue la saturación de información. La duración de las sesiones estuvo entre 60 y 90 minutos.

\section{ACERCAMIENTO AL GRUPO}

Los criterios más representativos estuvieron relacionados con los rasgos de creación que particularizan al grupo en la escena bayamesa, así como, las principales líneas de trabajo y desarrollo, también el impacto que ha tenido el grupo Alas D' Cuba y su papel en la creación teatral de la ciudad, destacándose diversidades de juicios y opiniones, los cuales fueron efectivos y positivos:

Se puede decir que "Teatro Alas D' Cuba" desde su surgimiento hasta la actualidad tiene una estética bien marcada, pues trabaja con una línea estética de pequeño formato recogiendo en sus obras textos de carácter universal con un lenguaje poético que lo diferencia y particulariza en el espectro teatral de la provincia explotando al máximo todos los recursos (Fernando Muñoz, director artístico Teatro D’Alas, 2013).

El mismo nos presenta temas muy bien elaborados asumiendo con obras que tienen una fortaleza probada por la historia $y$ de importantes autores. Las mismas se inclinan por trabajar con la psicología del ser humano adentrándose en los caracteres espirituales y morales de un pueblo o de una nación. Nos propone una escenografía desprovista de utilería, donde la cuarta pared se une a la comunicación que están dando los actores, apoyándose en las artes plásticas para darle a la escena una proyección diferente $y$ entretenida (Carlos Games, especialista del Consejo de Artes Escénicas de la ciudad de Bayamo, 2013).

Se infieren de estos criterios que uno de los rasgos que particulariza este teatro en la ciudad está precisamente en la capacidad de organización y gestión de una escena limpia de artificios y centrada en la cuarta pared o sea, el público, lo cual legitima los patrones escénicos, en una amplia gama de textos ofrecidos, escogidos adecuadamente y con una dosis de valentía al romper con patrones de creación establecidos en la escena bayamesa.

El contenido de sus obras constituye un reto para la puesta en escena, reluciendo en un contrapunteo entre lo que se escucha $y$ lo que se ve. Durante sus puestas 
se explotan las capacidades actorales al máximo logrando una complementación actor-escena-público. Sus obras son todo un ejercicio de expresión corporal, durante todo el montaje se puede apreciar la calidad del equipo actoral, el cual realiza entrenamientos bien cargados con técnicas actorales pertenecientes al teatro contemporáneo, utilizando el método Konstantín Stanislavski, Jerzy Grotowski, etc (Yanet Silveira, especialista de programación del Consejo de Artes Escénicas de la ciudad de Bayamo, 2013).

Sin lugar a dudas, se puede definir que a través de la utilización de los diferentes métodos y técnicas se busca formar al actor en artista, un actor que busque la verdad, que sea creador de su personaje y que busque en su interior las emociones que representa.

En este caso, el de Konstantín Stanislavski, actor y director ruso, fue el primero en articular de forma sistemática un método de actuación realista. Este movimiento teatral al igual que cualquier otro, surge como consecuencia o reacción a movimientos anteriores como es el caso de los estilos romántico, melodramático o el propio clásico, los cuales se identifican más con una actuación artificiosa sostenida por un estudiado uso de la voz y de la gestualidad, pero que no tenían nada que ver con la forma como los seres humanos se comportan socialmente.

Como todo movimiento, el método surge en estrecha relación con los avances en materia tecnológica, política, social y científica. Teniendo en consideración las circunstancias previas, provistas por el dramaturgo y el actor, se debe profundizar en el análisis del texto para conformar la mayor cantidad de referencias posibles que rodean al personaje, incluyendo su contacto con el medio ambiente, sus relaciones con los otros personajes, la relajación, la concentración, la memoria emocional y afectiva; es decir, a través de ejercicios, pretende conectar eventos en la vida del actor paralelo a la situación emocional en la obra con el fin de lograr interpretaciones realistas.
Por esta razón, se considera que el papel que le atribuye el grupo a la formación actoral, a la búsqueda individual, a la subjetividad $y$ al encontrarse a ellos mismos, es otra de las singularidades de este grupo, provocando una interacción simbólica a partir de sus metáforas teatrales que proveen no solo un espectáculo escénico, sino una creación deslumbrante y comprometida con la acción y con la reacción desde cada pieza actoral. Mediante las representaciones se propone un sistema a través del cual, el actor debe buscar y encontrar las causas internas de la manifestación exterior de los sentimientos.

El trabajo actoral y los riesgos que ponen en marcha, la experiencia de su director y por supuesto, las capacidades escénicas actorales son las principales características que dignifican la representación del grupo y sobre el particular, también fueron expresados los siguientes criterios:

Su contenido fundamental consiste en que el actor sienta el personaje, investigue, construya el antes y después de la vida del personaje al cual representa, buscando que el actor viva la obra, viva el momento como si fuera real, buscando en su archivo emotivo personal de experiencias vividas en su vida personal, logrando generar un vínculo entre la obra y el espectador. Sus textos aparecen con un alto contenido psicológico, que atrae a un público específico (poseedor de conocimientos) permitiéndole un espacio para la reflexión y el análisis de las mismas (Estrella Arias, especialista en desarrollo artístico del Consejo de Artes Escénicas de Bayamo, 2013).

Otro de los rasgos es la búsqueda de un público capaz de legitimar y comprender la acción teatral, en una interacción que parte del conocimiento y aceptación, así como la generación de sentimientos y expectativas que toda puesta debe llevar, implícito el sentimiento personal y la disposición desde cada actor a su compromiso con su público.

Por otro lado (a partir de las entrevistas a sujetos tipos) se respaldan las ideas sobre las cuestiones fundamentales y rasgos sobre su 
origen y desarrollo, el tema del repertorio y la calidad de montaje, producción y dirección.

Las obras se escogen a partir de un análisis minucioso por parte del director y los miembros del grupo. Aunque como somos un grupo bien abierto, muchas veces los miembros proponen obras, también realizan varias lecturas colectivas con varios textos hasta llegar a un consenso final, todo ello a través de un fuerte trabajo de mesa, donde se investiga y fundamenta los aspectos que forman parte de la obra partiendo de las características del autor, del contexto en que se escribe la obra, $y$ como ellos lo van a proponer partiendo de la intención del texto $y$ del mensaje que se quiere llevar a escena (Fernando Muñoz, director del grupo, 2013).

En cuanto a los temas, el grupo elige los de carácter universal, por ejemplo, el poder y la familia, los cuales son temas cubanos, apoyado en un lenguaje inteligente $y$ perspicaz, representando los diferentes estados de ánimos de los individuos y las personalidades de los personajes como consecuencia de una gran actuación.

En cuanto a la producción escenográfica del grupo, se puede señalar que el mismo propone un escenario simétrico, donde aparece una división de las diferentes áreas del escenario. Las realizaciones escenográficas, se caracterizan por el uso de materiales naturales combinados con materiales manuales, además de la implementación de contrastes de colores, formas $y$ figuras.

Nos propone la existencia de un teatro rico, utilizando al actor para iluminar el escenario, desprendiéndose de accesorios externos y proponiendo a una persona dispuesta a liberarse $y$ desprenderse del mundo material, buscando como motivación interna el amor y la entrega al teatro, quedando demostrado en las circunstancias en que fue creado el grupo, el cual surge como una necesidad de los actores de hacer un teatro de entrega, pasión, con rasgos diferentes $y$ alternativos (Fernando Muñoz, director del grupo, 2013).
El teatro en la provincia tiene una peculiaridad $y$ es que los colectivos son diferentes, en el caso de Alas se hace un teatro de salas, partiendo del trabajo del actor con las técnicas de Stanislavski, siendo un teatro más elaborado físicamente. Todo ello se evidencia en su manera de hacer teatro por la preparación física con que cuentan los miembros del grupo y lo cual se plasman en las representaciones, donde la expresividad del cuerpo es el protagónico: "Utilizan una escenografía de elementos decorativos y funcionales al mismo tiempo, como por ejemplo le dan diferentes utilidades a un solo objeto. El grupo preferentemente utiliza la escenografía funcional" (Grupo de discusión con miembros del grupo, 2013).

En cuanto a la escenografía, dirección y producción, se distinguen en la escena bayamesa por su innovación y por la propuesta de tipo de teatro, es decir, un teatro de vanguardia con la característica principal de utilizar el pequeño formato con elementos escenográficos que son escasos y el máximo de actores sean cinco.

\begin{abstract}
Alas en sus inicios surge con la primera intención de complementar el teatro en la provincia, estando configurado el teatro para niños, un grupo de teatro callejero, teatro de la montaña, teatro de salas marcado por la comedia, solamente faltaba el teatro de salas con un corte dramático, la tragedia, un teatro más contemporáneo lo cual lo diferencia del "Colectivo Teatral Granma" en cuanto a lo formal, en las facturas de las escenografías, en el trabajo corporal, que sobre todo es más tradicional y lo que está establecido $y$ formado de muchos años $y$ que tiene una forma bien definida $y$ aprobada (Grupo de discusión con miembros del grupo, 2013).
\end{abstract}

Se puede inferir que el Teatro Alas se diferencia del Colectivo Teatral Granma por ser más vanguardista y arriesgado, ya que trabaja con recursos novedosos a partir de la experimentación en el uso del cuerpo, la voz, un discurso teatral de mayor elaboración, que requiere un público con mayor nivel de preparación, rompiendo con la línea de la comedia 
que presenta el Colectivo Teatral Granma, para mostrar una puesta menos conservadora, atrevida, fresca, diferente, de pocos actores, sin abusar de recursos escenográficos, tomando en consideración el diseño de luces y la acentuada gestualidad, entre otros. Todos estos elementos fueron posibles de constatar a través de la observación participante, lo cual permitió un intercambio e interacción de la investigadora con los miembros del grupo, especialistas y público.

Asimismo, los miembros plantearon que un rasgo que los distingue y caracteriza es "la utilización del cuerpo como principal medio de creación, donde emerge una retroalimentación entre el actor y el espectador" (Grupo de discusión con miembros del grupo, 2013).

Al expresar dramáticamente el espectáculo, se hace con gran majestuosidad, proponiendo una dinámica intensa en la combinación cuerpo-voz-elementos escenográficos. Otras de las características que los distingue, es la creación en las puestas de una atmosfera alternativa, al decir de los participantes del grupo, consiste en un estado superior, un recurso en paralelo como una metáfora, reflejo de una búsqueda $y$ presentación de la cotidianidad representada con matices propios, ajenos a lo real objetivo, con total independencia en el escenario, constituye un abandono total de la realidad para convertirse en otros en otra dimensión, recurriendo a los resortes expresivos del actor y se aumenta la diversidad estética de sus miembros y puestas.

\section{CONSIDERACIONES FINALES}

Se concluye que en la investigación, a partir del empleo de los métodos, el análisis de documentos $y$ otras fuentes, se pudo constatar una dimensión histórica teatral de la ciudad de Bayamo, permitiendo una caracterización del teatro profesional en la misma, en su devenir histórico social, denotando los elementos significativos del mismo y los vacíos sobre un arte escénico propio y nacionalista sobre todo en las etapas colonial y neocolonial.

También permitió acercarse al grupo profesional de teatro "Alas D'Cuba" de la ciudad de Bayamo y declarar sus principales elementos de desarrollo, línea de creación, aportes y limitaciones en un recorrido desde su fundación hasta la actualidad.

Los rasgos distintivos del grupo Alas D' Cuba dentro de la creación teatral bayamesa, se denotan a partir de elementos tales como: teatro de texto y universal, para adultos $y$ en salas, promoviendo un análisis bidireccional (actorpúblico) a la búsqueda de una interacción que legitime los presupuestos y que logre la apropiación de la subjetividad actoral y sus desafíos.

Es una creación que se distingue por romper en el panorama bayamés del teatro, con valor e innovación sin precedentes, que aboga por una escena comprometida con la universalidad de la representación, pasando por la formación de una estética marcada por la diversidad y la búsqueda de un nuevo patrón teatral en la ciudad: grupo de pequeño formato, la utilización del cuerpo, el intercambio con el público, la escenografía y el sentimiento personal bajo una dirección competente y a la búsqueda de un teatro de mayor elaboración y aceptación.

\section{BIBLIOGRAFÍA}

Alonso, Francisco. Teatro. La Habana: Editorial Letras Cubanas, 1981.

Barba y N. Savarese. Antropología Teatral 4. 1982: 81.

Céspedes Argote, Onoria y Chávez Pardo, Eduardo. Bayamo síntesis histórica. Bayamo, Cuba: Editorial José Joaquín Palma, 1989.

Cobas Sanz, Mario. "Bayamo y la Sociedad Filarmónica en el siglo xix". Ventana sur (6). Julio-diciembre, 2008: 22-27.

Fonseca García, Ludín B. La historia en la palabra: la historia en las revistas culturales 1. Bayamo-Granma: Editorial Bayamo, 2005.

Fonseca García, Ludín B. y Naranjo Tamayo, Aldo Daniel. Síntesis histórica municipal Bayamo. La Habana, Cuba: Editora Historia. Instituto de Historia de Cuba, 2011.

Fonseca García, Ludín B. y Yero Masdeu, José Manuel. La historia en la palabra $V$ : formación y desarrollo identitario. Bayamo-Granma, Cuba: Ediciones Crisol, 2008. 
Giraud, Heriberta Albisa; Franco, Aldo Alonso y La Paz Pelletier, Felix. Historia del teatro. La Habana, Cuba: Editorial Pueblo y Educación, 1998.

González Curquejo, A. Breve ojeada al teatro cubano a través de los siglos (1820-1920). La Habana, Cuba: La Universal, 1923.

González Freyre, Naty. "Colectivo teatral: la cultura en Granma”. Bohemia 72. La Habana, 7 de noviembre, 1980.

Hernández Sampier, Roberto. Metodología de la investigación I. La Habana, Cuba: Editorial Félix Varela, 2003 a.

Hernández Sampier, Roberto. Metodología de la investigación II. La Habana, Cuba: Editorial Félix Varela, 2003 b.

Iglesias Figueredo, Leticia. "Colectivo Teatral Granma", agente transformador del desarrollo teatral granmense. [Trabajo de Diploma]. 2011.

Lago Vieito, Ángel. Bayamo en el crisol de la nacionalidad cubana. Bayamo, Cuba: Ediciones Bayamo, 1996.

Leal, Rine. Teatro mambí. Editorial Letras Cubanas, 1978.

Leal, Rine. La selva oscura. La Habana, Cuba: Editorial Arte y Literatura, 1982.

Leal, Rine. Teatro Bufo siglo xIx. La Habana, Cuba: Instituto Cubano del Libro, 1989.

Leal, Rine. Breve historia del teatro cubano. La Habana, Cuba: Editorial Félix Varela, 2004.

Maceo Verdecia, José. Bayamo. Bayamo, Cuba: Ediciones Bayamo, 2009.

Mary Aguilera, Idelmis. Fuego y acaso. Bayamo, Cuba: Ediciones Bayamo, 2006.

Muñoz Carrazana, Fernando. Treinta años de teatro profesional en Granma. Una propuesta de periodización. Granma, Cuba: Ediciones Bayamo, 2007.

Naranjo, Aldo Daniel. Contextualización de Bayamo en la Colonia. 2010.

Pavis, Patrice. Diccionario del teatro. Tomo I. Ed. Revolucionaria, 1988: 68.

Pita, Santiago. El príncipe jardinero y fingido Cloridano. La Habana, Cuba: Editorial Arte y Literatura, 1975.
Robreño, Eduardo. Historia del teatro popular cubano. La Habana, Cuba: Editorial Pueblo y Educación, 1984.

Rodríguez Gómez, Gregorio. Metodología de la investigación cualitativa. La Habana, Cuba: Editorial Félix Varela, 2004.

Rodríguez López, Dayami. "Las sociedades de recreo en la Cultura Bayamesa". Ventana Sur 4. Enero-diciembre, 2007: 15-19.

Taquechel Larramandi, Isabel; Suarez Suarez, Luis Carlos; Roja Bez, Jose; Bernal Hernandez, Arquelio; Martinez Boffill, Lidia; Valdes Curreros, Oscar y Solís, Mercedes. "Unidad de producción" 1. Apreciación de la Cultura Cubana II. Cuba: Ministerio de Educación Superior. Cuba.Imprenta Andre Voisin, 1986.

Taylor, S.J. y Bodgan, R. Introducción a los métodos cualitativos de investigación. La Habana, Cuba: Editorial Félix Varela, 2002 .

\section{ENTREVISTAS}

Carlos Games. Especialista del Consejo de Artes Escénicas de la ciudad de Bayamo. Consejo de Artes Escénicas de la ciudad de Bayamo. Abril 2013.

Estrella Arias Piña. Especialista en desarrollo artístico del Consejo de Artes Escénicas de la ciudad de Bayamo. Consejo de Artes Escénicas de Bayamo. Abril 2013.

Fernando Muñoz Carrazana. Director artístico del grupo. Sala Teatro José Joaquín Palma. Bayamo, abril 2013.

Fernando Muñoz Carrazana. Director del grupo. Sala Teatro José Joaquín Palma. Mayo 2013.

Grupo de discusión con miembros del grupo. Sala teatro José Joaquín Palma. Bayamo. Febrero 2013.

Yanet Silveira. Especialista de Programación del Consejo de Artes Escénicas de la ciudad de Bayamo. Consejo de Artes Escénicas de Bayamo. Mayo 2013. 


\section{ANEXOS}

\section{ANEXO 1: GUÍA DE ENTREVISTAS EN PROFUNDIDAD}

Objetivo: Obtener información sobre aspectos importantes relacionados con los rasgos que particularizan la creación del grupo Teatro Alas D' Cuba de la ciudad de Bayamo.

Objeto: los expertos

Tipología: en profundidad

Cuestiones de indagación: profesionales

Guía temática:

$\diamond \quad$ Producción, montaje y escenografía

$\diamond \quad$ Dirección, repertorio y puesta en escena

$\diamond \quad$ Temas, técnica de montaje y elementos que lo identifican $y$ hacen diferente entre los grupos de la ciudad

$\diamond \quad$ Consideraciones generales respecto a la realización del estudio

\section{ANEXO 2: GUÍA DE ENTREVISTAS EN PROFUNDIDAD}

Objetivo: Obtener información sobre aspectos importantes relacionados con los rasgos que particularizan la creación del grupo Teatro Alas D' Cuba de la ciudad de Bayamo.

Objeto: los sujetos tipos (miembros del grupo y fundadores)

Tipología: en profundidad

Cuestiones de indagación: profesionales

Guía temática:

$\diamond \quad$ Clima que se genera durante el trabajo grupal, ya sea en montaje o presentación

$\diamond \quad$ Calidad de la escena que se proyecta, de los temas y de la dirección

$\diamond \quad$ Limitaciones en la producción

$\diamond \quad$ Versatilidad actoral a tener en cuenta que hace diferente esta creación

$\diamond \quad$ Consideraciones generales respecto a la realización del estudio

\section{ANEXO 3: GRUPO DE DISCUSIÓN}

\section{SESIÓN 1}

Familiarización con el grupo.

Lugar: Sala Teatro José Joaquín Palma.

Hora: 3:00 pm.

Tiempo de duración: 1 hora.

Participantes: investigadoras, director artístico, actores $y$ productora.

Ejes temáticos:

$\diamond \quad$ Presentación de la idea de investigación

$\diamond \quad$ Aclaración de dudas

$\diamond \quad$ Debate sobre el surgimiento del grupo, tratamiento a las temáticas, puestas $y$ producción escénica

$\diamond \quad$ Planteamientos de limitaciones $y$ dificultades

$\diamond \quad$ Otros tópicos que surjan del intercambio

\section{SESIÓN 2 Y 3}

Lugar: Teatro 10 de octubre (local de ensayo)

Hora: 10:00 am.

Tiempo de duración: 1 hora y $30 \mathrm{~min}$.

Participantes: investigadoras, director artístico, actores, productora $y$ fundadores.

Ejes temáticos:

$\diamond \quad$ Producción, montaje y escenografía

$\diamond \quad$ Texto para la puesta $y$ dirección escénica

$\diamond \quad$ Fortalezas del elenco

$\diamond \quad$ Aportes a la dramaturgia cubana

$\diamond \quad$ Limitaciones

$\diamond \quad$ Ideas, propuestas $y$ debate que se genere

$\diamond$ Conclusiones: en las mismas las investigadoras, agradecen la ayuda $y$ colaboración, presentan algunas conclusiones obtenidas del intercambio, se realizan los ajustes necesarios a los tópicos tratados.

Fecha de ingreso: 20/06/2013 Fecha de aprobación: 30/09/13 